\title{
Apparent zinc absorption by rats from foods labelled intrinsically and extrinsically with ${ }^{67} \mathrm{Zn}$
}

\author{
BY SUSAN J. FAIRWEATHER-TAIT, THOMAS E. FOX, \\ S. GABRIELLE WHARF AND JOHN EAGLES \\ AFRC Institute of Food Research, Colney Lane, Norwich NR4 $7 U A$ \\ AND HELEN M. CREWS AND ROBERT MASSEY \\ MAFF Food Safety Directorate, Food Science Laboratory, Colney Lane, Norwich NR4 $7 U Q$
}

(Received 11 May 1990 - Accepted 6 November 1990)

\begin{abstract}
A variety of foods (peas (Pisum sativum), chicken meat, eggs, goat's milk, human milk) enriched with the stable isotope ${ }^{67} \mathrm{Zn}$ were prepared by means of intrinsic- and extrinsic-labelling procedures. They were fed to rats and apparent absorption of ${ }^{67} \mathrm{Zn}$ determined from faecal excretion measurements using thermal ionization mass spectrometry. There were significant differences in the absorption of the extrinsic and intrinsic label which differed in magnitude between the foods tested. The extrinsic ${ }^{67} \mathrm{Zn}$ was less well absorbed in peas, chicken meat, eggs, and human milk than intrinsic ${ }^{67} \mathrm{Zn}$, but in goat's milk the extrinsic ${ }^{67} \mathrm{Zn}$ was better absorbed than the intrinsic label. These results demonstrate that extrinsically-added stable $\mathrm{Zn}$ isotopes do not fully exchange with endogenous $\mathrm{Zn}$ in many foods, and illustrate the need for caution when using extrinsic labels for $\mathrm{Zn}$ bioavailability studies.
\end{abstract}

$\mathrm{Zn}$ absorption: Stable $\mathrm{Zn}$ isotopes: Intrinsic and extrinsic labelling: $\mathrm{Zn}$ bioavailability

Extrinsic labelling with isotopes of iron for bioavailability studies has been an accepted method for nearly two decades (Bothwell et al. 1979). With the more recent interest in zinc nutrition, a few studies have been made in different laboratories to investigate the use of extrinsic labels for $\mathrm{Zn}$ bioavailability studies, but as yet the validity of this technique remains unresolved. The extrinsic technique has several clear advantages; the preparation of foodstuffs for consumption is much simpler, and less isotope is required. For radioisotopes, extrinsic labelling is safer and the problems of radioactive decay are less of a feature in experimental design, but in studies using stable isotopes, cost becomes a more important consideration. With plant materials, there is no good way of incorporating isotope efficiently into the plant, and inevitably a high proportion of the isotope goes to waste using the intrinsic technique. The same is true, but to a lesser extent, in foods of animal origin. Therefore, there is much to be gained if extrinsic labelling methods can be used. The present study was designed to compare the two labelling techniques, by measuring apparent $\mathrm{Zn}$ absorption in rats from a range of intrinsically- and extrinsically${ }^{67} \mathrm{Zn}$-labelled foods.

\section{MATERIALS AND METHODS}

Animals and diets

In all experiments male Wistar rats were used, weighing $180-260 \mathrm{~g}$ at the time of the test meal. For each food tested, animals from the same batch were allocated randomly into two groups (usually fifteen rats/group), one given the intrinsically-labelled food and the other the extrinsically-labelled food. Throughout the study, each animal was individually caged 
Table 1. Composition of the semi-synthetic diet given to rats $(\mathrm{g} / \mathrm{kg}$ diet $)$

\begin{tabular}{lll} 
& Maize starch & 309 \\
& Sucrose & 309 \\
& Casein & 200 \\
& Cellulose* & 40 \\
& Maize oil & 80 \\
& Mineral mix $\dagger$ & 40 \\
& Vitamin mix & 20 \\
& DL-methionine & $2 \cdot 5$ \\
\hline
\end{tabular}

* Solka floc ${ }^{\circledR}$ (Johnson, Jurgenson \& Wettre).

$\dagger$ Mineral mix (g/kg diet) : $\mathrm{CaHPO}_{4} 13 \cdot 0, \mathrm{CaCO}_{3} 8 \cdot 2, \mathrm{Na}_{2} \mathrm{HPO}_{4} 7 \cdot 4, \mathrm{KCl} 7 \cdot 03, \mathrm{MgSO}_{4} \cdot \mathrm{H}_{2} \mathrm{O} 4 \cdot 0, \mathrm{MnSO}_{4} \cdot \mathrm{H}_{2} \mathrm{O}$ $0 \cdot 18, \mathrm{FeSO}_{4} .7 \mathrm{H}_{2} \mathrm{O} 0 \cdot 144, \mathrm{ZnCO}_{3} 0 \cdot 025, \mathrm{CuSO}_{4} .5 \mathrm{H}_{2} \mathrm{O} 0 \cdot 023, \mathrm{KIO}_{3} 0 \cdot 001$.

\$ Vitamin mix (g/kg diet): nicotinic acid 60, cyanocobalamin (in mannitol) (Glaxo) 50, calcium-D-pantothenate 40 , thiamin hydrochloride 10 , riboflavin 10 , pyridoxine 10 , pteroylmonoglutamic acid 10 , D-biotin 1 , phylloquinone (in lactose) 2, Rovimix E-50 150 (containing $75 \mathrm{mg}$ DL- $\alpha$-tocopherol acetate), Rovimix A-500 25 (containing $3.75 \mathrm{mg}$ retinol), Rovimix D3-500 15 (containing $188 \mu \mathrm{g}$ cholecalciferol) (all Rovimix products from Roche), choline bitartrate 1800 , starch (bulking agent) 17817.

in a plastic and stainless-steel cage with wire-gridded bottom, fed on semi-synthetic control diet (Table 1) and trained to meal-feed during the $9 \mathrm{~d}$ preceding the test meal. The day after the test meal they were fed on low- $\mathrm{Zn}$ semi-synthetic diet which was similar to that described in Table 1 but without added $\mathrm{Zn}$. This was to reduce the level of endogenous $\mathrm{Zn}$ excretion and, hence, minimize the re-excretion of ${ }^{67} \mathrm{Zn}$ absorbed from the test meal (Fairweather-Tait et al. 1985).

\section{Administration of ${ }^{67} \mathrm{Zn}$-labelled meals}

The ${ }^{67} \mathrm{Zn}$-labelled foods were prepared as described elsewhere (Fox et al. 1991). The isotope had either been incorporated into the food previously or was added to non-enriched food as a solution of elemental $\mathrm{Zn}\left(91.9 \%{ }^{67} \mathrm{Zn}\right.$ (atom \%); Technical and Optical Equipment, Edgware Road, London NW9 6EE) in dilute hydrochloric acid (AR) at least $1 \mathrm{~h}$ before consumption.

(a) Peas were harvested, removed from their pods, freeze-dried and ground to a fine powder in a Moulinex coffee-grinder.

(b) Chicken meat was removed from the carcass, discarding any muscle near the site of ${ }^{67} \mathrm{Zn}$ injection, cooked in a microwave oven, minced, freeze-dried and ground to a fine powder.

(c) Eggs were beaten and cooked as scrambled egg in a microwave oven, freeze-dried and ground to a fine powder.

(d) Goat's and human milk were freeze-dried and ground to a fine powder.

After an overnight fast, each rat was given a meal of freeze-dried food, labelled with the stable isotope ${ }^{67} \mathrm{Zn}$, mixed to a paste with distilled water. Weights and descriptions of test meals are given in Table 2. Chromium oxide $(5 \mathrm{mg} / \mathrm{g}$ food) was also added to the meal as a faecal marker. The meals were mixed thoroughly before offering them to the rats, and any uneaten food was dried, weighed and the weight deducted from the initial weight in order to calculate the exact intake of ${ }^{67} \mathrm{Zn}$ label.

\section{Measurement of apparent ${ }^{67} \mathrm{Zn}$ absorption}

A complete faecal collection was made for each rat starting on the day of the test meal and finished 1-2 d after the $\mathrm{Cr}_{2} \mathrm{O}_{3}$ had been excreted, a total period of 5-6 d. The faeces were dried, ground and heated to $480^{\circ}$ in silica crucibles for $48 \mathrm{~h}$. Samples of both intrinsically- 
Table 2. Details of test meals fed to rats

\begin{tabular}{|c|c|c|c|c|c|c|c|}
\hline \multirow[b]{2}{*}{ Food } & \multirow[b]{2}{*}{$\begin{array}{c}\text { Dry wt } \\
\text { (g) }\end{array}$} & \multicolumn{3}{|c|}{ Intrinsically-labelled } & \multicolumn{3}{|c|}{ Extrinsically-labelled } \\
\hline & & $\underset{(\mu \mathrm{g} / \mathrm{g})}{\mathrm{Zn}}$ & $\begin{array}{c}{ }^{67} \mathrm{Zn} \\
(\mu \mathrm{g} / \mathrm{g})\end{array}$ & $R^{*}$ & $\underset{(\mu \mathrm{g} / \mathrm{g})}{\mathrm{Zn}}$ & $\begin{array}{c}{ }^{67} \mathrm{Zn} \\
(\mu \mathrm{g} / \mathrm{g})\end{array}$ & $R^{*}$ \\
\hline Peas (Pisum sativum) & 6 & 46 & $6 \cdot 5$ & $2 \cdot 62$ & 46 & $2 \cdot 3$ & $5 \cdot 51$ \\
\hline Chicken meat & 6 & 53 & $6 \cdot 3$ & 3.05 & 53 & $4 \cdot 4$ & $4 \cdot 00$ \\
\hline Eggs & 5 & 30 & $5 \cdot 2$ & $2 \cdot 17$ & 34 & $1 \cdot 4$ & $6 \cdot 11$ \\
\hline Goat's milk & 7 & 40 & $4 \cdot 4$ & $3 \cdot 21$ & 29 & $0 \cdot 9$ & $6 \cdot 88$ \\
\hline Human milk & 5 & 7 & $0 \cdot 2$ & 6.87 & 12 & $3 \cdot 2$ & $1 \cdot 34$ \\
\hline
\end{tabular}

$R,{ }^{64} \mathrm{Zn}:{ }^{67} \mathrm{Zn}$ (for details of calculation, see below).

${ }^{*}$ Non-enriched (naturally-occurring) ${ }^{64} \mathrm{Zn}:{ }^{67} \mathrm{Zn}$ ratio $11 \cdot 85$.

and extrinsically-labelled foods were treated similarly. Portions of the resultant ash were analysed for total $\mathrm{Zn}(\mathrm{T})$ by atomic absorption spectrometry (AAS) $(0.025 \mathrm{~g}$; FairweatherTait \& Southon, 1989) and ${ }^{67} \mathrm{Zn}$ by thermal ionization mass spectrometry $(0 \cdot 2-0 \cdot 25 \mathrm{~g}$, see below). Apparent $\mathrm{Zn}$ absorption was calculated as the difference between intake and faecal excretion of the ${ }^{67} \mathrm{Zn}$ label.

\section{Thermal ionization mass spectrometry}

The ashed faeces or food samples were subjected to a clean-up procedure before isotope measurement by mass spectrometry, as described previously (Fairweather-Tait et al. 1989). Fractions of $1.5 \mathrm{ml}$ were collected and subjected to analysis by thermal ionization mass spectrometry (THQ; Finnigan-MAT, Bremen, Germany). The ratio $(R)$ between ${ }^{64} \mathrm{Zn}$ (natural abundance 48.6 atom $\%$ ) and ${ }^{67} \mathrm{Zn}$ (natural abundance 4.1 atom $\%$ ) was measured (Eagles et al. 1989), corrected for isotopic fractionation, and inserted into the following formula:

$$
R=\frac{\frac{48 \cdot 6}{65 \cdot 39} x+\frac{1 \cdot 2}{67 \cdot 02} y}{\frac{4 \cdot 1}{65 \cdot 39} x+\frac{91 \cdot 9}{67 \cdot 02} y}
$$

where $x$ is the weight of all isotopes of natural $\mathrm{Zn}$ (average molecular weight 65.39), $y$ is the weight of all isotopes of the enriched $\mathrm{Zn}$ (average molecular weight 67.02). By substituting the AAS value for total $\mathrm{Zn}$ into the formula (where $T=x+y(65 \cdot 39 / 67 \cdot 02)$ ), $y$ (the weight of enriched isotope over and above natural abundance) was then calculated.

\section{Statistical analysis}

The ${ }^{67} \mathrm{Zn}$ apparent absorption values from each intrinsically- and extrinsically-labelled food were compared by Student's $t$ test. The complete set of data were analysed by twoway analysis of variance (ANOVA) using a GENSTAT program (Payne et al. 1987).

\section{RESULTS}

For each food under study there were no differences between the mean rat body-weight in the intrinsically- and extrinsically-labelled treatment groups (Table 3).

The degree of ${ }^{67} \mathrm{Zn}$ enrichment achieved by intrinsic labelling $(R)$ differed between the various foods (Table 2). It was highest in the eggs, about 5-fold, and lowest in human milk, 
Table 3. Body weights of groups of rats fed on ${ }^{67} \mathrm{Zn}$ intrinsically-labelled $(\mathrm{I})$ or extrinsically-labelled $(E)$ foods on the day of the test meal*

(Mean values with their standard errors)

\begin{tabular}{|c|c|c|c|}
\hline \multirow[b]{2}{*}{ Food } & \multirow[b]{2}{*}{$n$} & \multicolumn{2}{|c|}{ Body-wt (g) } \\
\hline & & Mean & SE \\
\hline \multicolumn{4}{|c|}{ Peas (Pisum sativum) } \\
\hline I & 15 & 210 & 5 \\
\hline $\mathrm{E}$ & 15 & 219 & 9 \\
\hline \multicolumn{4}{|c|}{ Chicken meat } \\
\hline I & 15 & 259 & 5 \\
\hline $\mathrm{E}$ & 15 & 260 & 3 \\
\hline \multicolumn{4}{|l|}{ Eggs } \\
\hline I & 15 & 201 & 3 \\
\hline $\mathrm{E}$ & 15 & 199 & 3 \\
\hline \multicolumn{4}{|c|}{ Goat's milk } \\
\hline I & 16 & 182 & 6 \\
\hline $\mathrm{E}$ & 15 & 179 & 4 \\
\hline \multicolumn{4}{|c|}{ Human milk } \\
\hline I & 10 & 218 & 4 \\
\hline $\mathrm{E}$ & 10 & 218 & 3 \\
\hline
\end{tabular}

* For details of procedures, see p. 66 .

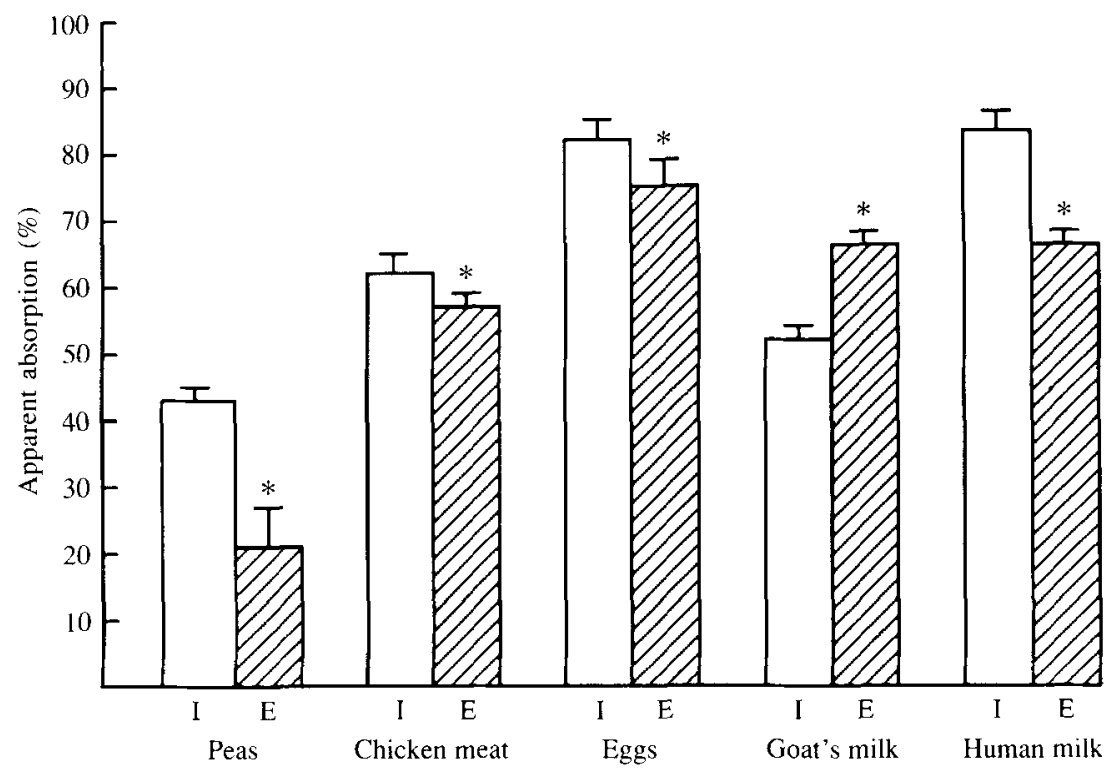

(Pisum sativum)

Fig. 1. Comparison between apparent ${ }^{67} \mathrm{Zn}$ absorption in rats from intrinsically- $(\mathrm{I} ; \square)$ and extrinsically-labelled $(E ; \square)$ foods. Values are means with their standard errors represented by vertical bars. Mean values for I foods were significantly different from those for $\mathrm{E}$ foods: ${ }^{*} P<0.05$. For details of procedures, see p. 66 . 
less than 2-fold. Every effort was made when adding the extrinsic label to keep the levels as low as possible in order to obtain foods with similar $\mathrm{Zn}$ concentrations. In general the amount of $\mathrm{Zn}$ in the pairs of foods was fairly similar.

Apparent absorption of ${ }^{67} \mathrm{Zn}$ from the intrinsically-labelled foods is shown in Fig. $1 . \mathrm{Zn}$ absorption was lowest from peas and highest from human milk, followed closely by eggs. Goat's milk contained $\mathrm{Zn}$ of lower bioavailability. Absorption from the extrinsicallylabelled foods was significantly different in all instances, being lower for chicken meat, peas, eggs and human milk, and higher for goat's milk. The magnitude of difference between the two types of labelled foods was least in the chicken meat, where it only just reached statistical significance $(t 2.168, P<0.05)$, followed by eggs $(t 2.427, P<0.025)$, and was greatest in human milk $(t 7.45, P<0.001)$, followed by peas $(t 4.72, P<0.001)$.

Two-way ANOVA of the $\mathrm{Zn}$ absorption data (food and type of label) showed that the variation was attributable to the food source $(F 151 \cdot 1, P<0.001)$ and, to a lesser extent, the type of labelling technique used $(F$ 23.0, $P<0.001)$. There was also a food-label interaction $(F 19 \cdot 5, P<0.001)$. The food effect was by far the greatest, and the strength of the effect of intrinsic-extrinsic labelling on $\mathrm{Zn}$ absorption differed between the foods.

\section{DISCUSSION}

Most of the published studies on labelling techniques for $\mathrm{Zn}$ have utilized the radio-isotope ${ }^{65} \mathrm{Zn}$ rather than stable isotopes. When using ${ }^{65} \mathrm{Zn}$ as an extrinsic label, the contribution made by the isotope to the total $\mathrm{Zn}$ level is negligible because most ${ }^{65} \mathrm{Zn}$ is virtually carrierfree. However, the amount of stable isotope needed to obtain measurable enrichment of a test food results in an inevitable increase in the $\mathrm{Zn}$ content of the food. The efficiency of absorption of $\mathrm{Zn}$, like other minerals, falls with increasing dose, but at low intakes percentage absorption appears to be unrelated to dose. In Wistar rats weighing $250 \mathrm{~g}$, fed semi-synthetic control diet, there is a linear fall from 250 to $1000 \mathrm{mg}$, which only reaches significance at $750 \mathrm{mg}$ (Fairweather-Tait \& Southon, 1989). The maximum dose of $\mathrm{Zn}$ given in the present study was $320 \mu \mathrm{g}$, which is well within this limit, thus reducing the possibility of size of dose affecting the results.

There are only a few published studies addressing the question of extrinsic labelling with Zn using rats (Evans \& Johnson, 1977; Meyer et al. 1983; Ketelsen et al. 1984) or humans (Janghorbani et al. 1982; Flanagan et al. 1985; Gallaher et al. 1988; Serfass et al. 1989). The consensus of opinion seems to be that this is a valid technique, as only one study cast doubt on the method (Janghorbani et al. 1982). However, the results from the present study do not support this conclusion. Close examination of the findings from the studies listed previously gives some indication as to why no differences between extrinsic and intrinsic labels have been reported. Flanagan et al. (1985) gave extrinsically-labelled turkey meat to human subjects on two occasions $8 \mathrm{~d}$ apart and showed that the mean absorption was similar. However, when they investigated the repeatability of the test they found a high degree of variation in $\mathrm{Zn}$ absorption within individuals on separate occasions. Regression analysis of the results showed no correlation between intrinsic and extrinsic values $(r 0.15, P>0.05)$. Very similar results were found in a study by Gallaher et al. (1988) where the correlation between intrinsic and extrinsic labels in beef was also not significant $(r 0 \cdot 14$, $P>0.05$ ).

The design of labelling studies depends on which isotopes are being used. As there is only one radioisotope of practical importance, ${ }^{65} \mathrm{Zn}$, either subjects must receive two test meals separated by a number of days, or two groups of subject must be employed. The former has the disadvantage of inter-test variability described previously, and the latter requires two matched groups, a difficult objective in human studies but easily achievable with in- 
bred rats as used in the present study. Alternatively, stable isotopes can be used to label foods, incorporating one isotope intrinsically and a different isotope extrinsically. Such a study was performed recently by Serfass et al. (1989) in which no difference was found between the intrinsic and extrinsic label. Two isotopes $\left({ }^{67} \mathrm{Zn}\right.$ and $\left.{ }^{70} \mathrm{Zn}\right)$ were used to produce double-labelled infant formula which was fed to infants and absorption estimated by stool collection for $72 \mathrm{~h}$. The fact that the milk was fed as a reconstituted formula, equilibrated for a minimum of $20 \mathrm{~h}$, may explain the difference in findings between this study and the present study.

The time-period required for an extrinsic label to equilibrate with endogenous mineral has been debated in the literature. In liquid systems, there is a real possibility that such an exchange occurs before the food is consumed. Sandstrom et al. (1983) examined the movement of ${ }^{65} \mathrm{Zn}$ added to milk and left to incubate for 30 min using ultracentrifugation, ultrafiltration and gel filtration, and found that it behaved in a manner analogous to native $\mathrm{Zn}$. Most, if not all, $\mathrm{Zn}$ in foods is complexed with peptides, proteins, metalloenzymes, organic acids, and a number of other binding compounds. In a non-aqueous environment, even if the native $\mathrm{Zn}$ is only loosely bound, it is highly unlikely that added $\mathrm{Zn}$ isotopes come into close enough contact with the native $\mathrm{Zn}$ to exchange fully.

The foods used in the present study were freeze-dried, weighed into small glass dishes and made into a paste with distilled water $1 \mathrm{~h}$ before consumption. This is a convenient method for feeding rats which ensures that most of the food is eaten and enables any waste to be measured precisely. The milk powder was treated in a similar fashion because of the difficulties associated with the quantitative feeding of fluids; administration by gavage had been ruled out as being stressful to the animals and possibly affecting subsequent absorption of $\mathrm{Zn}$. Several physiological factors may be partly responsible for the differences in the behaviour of the extrinsic label in different foods. For example, residence time of the test meals in the stomach and small intestinal tract may have determined the degree of exchange that occurred between the added isotope and native $\mathrm{Zn}$. It is likely that milk passed through the stomach and small intestine more rapidly than the other foods (reducing the possibility of exchange?) but, on the other hand, its high digestibility may have released the $\mathrm{Zn}$ more rapidly than, for example, is the case with peas. The presence and nature of binding substances, such as phytate, may influence the rate at which extrinsic and intrinsic $\mathrm{Zn}$ is released for absorption.

Another important consideration is the physical state of the food. Since liquids pass through the intestinal tract more rapidly than solid material, any isotope carried in the liquid phase will be absorbed at a different time and possibly at a different site from isotope carried in the solid phase. Extrinsic isotope is added as a solution and, therefore, may generally be associated with the liquid phase, whereas intrinsic isotope is more likely to be bound to the insoluble fraction of the food. Thus, the explanation for differences between foods probably relates to the tightness with which the native $\mathrm{Zn}$ is bound to the food constituents, as modified by the particular intestinal conditions to which the food is exposed.

When the $\mathrm{Zn}$ absorption results for intrinsically- and extrinsically-labelled foods were subjected to two-way ANOVA, the variance was explained by both the type of labelling and the particular food under examination, as well as a food-label interaction. The fact that there were significant differences in $\mathrm{Zn}$ absorption between the pairs of foods tested indicates that isotopic exchange was not complete. Despite the fact that the composition of the food itself seemed to have a more profound effect on apparent $\mathrm{Zn}$ absorption than the method of labelling, the results show that intrinsically- and extrinsically-labelled foods may provide different answers. Thus, although extrinsic labels may be used as an approximate guide when assessing the bioavailability of $\mathrm{Zn}$ from different foods or meals, 
they cannot be used to predict absolute values for absorption. The latter can only be obtained from intrinsically-labelled food, or from extrinsically-labelled material after proper validation.

The work was supported by the Ministry of Agriculture, Fisheries and Food.

\section{REFERENCES}

Bothwell, T. H., Charlton, R. W., Cook, J. D. \& Finch, C. A. (1979). Iron Metabolism in Man, pp. 256-260. Oxford: Blackwell.

Eagles, J., Fairweather-Tait, S. J., Portwood, D. E., Self, R., Gotz, A. \& Heumann, K. G. (1989). Comparison of fast atom bombardment mass spectrometry and thermal ionization quadrupole mass spectrometry for the measurement of zinc absorption in human nutrition studies. Analytical Chemistry 61, 1023-1025.

Evans, F. W. \& Johnson, P. E. (1977). Determination of zinc availability in foods by the extrinsic label technique. American Journal of Clinical Nutrition 30, 873-878.

Fairweather-Tait, S. J., Portwood, D. E., Symss, L., Eagles, I. \& Minski, M. J. (1989). Iron and zinc absorption in human subjects from a mixed meal of extruded and non-extruded wheat bran and flour. American Journal of Clinical Nutrition 49, 151-155.

Fairweather-Tait, S. J. \& Southon, S. (1989). Studies of iron:zinc interactions in adult rats and the effect of iron fortification of two commercial infant weaning products on iron and zinc status of weanling rats. Journal of Nutrition 119, 599-606.

Fairweather-Tait, S. J., Wright, A. J. A., Cooke, J. \& Franklin, J. (1985). Studies of zinc metabolism in pregnant and lactating rats. British Journal of Nutrition 54, 401-413.

Flanagan, P. R., Cluett, J., Chamberlain, M. J. \& Valberg, L. S. (1985). Dual-isotope method for determination of human zinc absorption: the use of a test meal of turkey meat. Journal of Nutrition 115, 111-122.

Fox, T. E., Fairweather-Tait, S. J., Eagles, J. \& Wharf, S. G. (1991). Intrinsic labelling of different foods with stable isotope of zinc $\left({ }^{67} \mathrm{Zn}\right)$ for use in bioavailability studies. British Journal of Nutrition 66, 57--63.

Gallaher, D. D., Johnson, P. E., Hunt, J. R., Lykken, G. I. \& Marchello, M. J. (1988). Bioavailability in humans of zinc from beef: intrinsic vs extrinsic labels. American Journal of Clinical Nutrition 48, 350-354

Janghorbani, M., Istfan, N. W., Pagounes, J. O., Steinke, F. H. \& Young, V. R. (1982). Absorption of dietary zinc in man: comparison of intrinsic and extrinsic labels using a triple stable isotope method. American Journal of Clinical Nutrition 36, 537-.545.

Ketelsen, S. M., Stuart, M. A., Weaver, C. M., Forbes, R. M. \& Erdman J. W. Jr. (1984). Bioavailability of zinc to rats from defatted soy flour, acid-precipitated soy concentrate as determined by intrinsic and extrinsic labelling techniques. Journal of Nutrition 114, 536-542.

Meyer, N. R., Stuart, M. A. \& Weaver, C. M. (1983). Bioavailability of zinc from defatted soy flour, soy hulls and whole eggs as determined by intrinsic and extrinsic labelling techniques. Journal of Nutrition 113, 1255-1264.

Payne, R. W., Lane, P. W., Ainsley, A. E., Bicknell, K. E., Digby, P. G. N., Harding, S. A., Leech, P. K., Simpson, H. R., Todd, A. D., Verrier, P. J., White, R. P., Gower, J. C., Tunnicliffe-Wilson, G. \& Paterson, L. J. (1987) GENSTAT 5 Reference Manual. Oxford: Clarendon Press.

Sandstrom, B., Keen, C. L. \& Lonnerdal, V. (1983). An experimental model for studies of zinc bioavailability from milk and infant formulas using extrinsic labelling. American Journal of Clinical Nutrition 38, 420-428.

Serfass, R. E., Ziegler, E. E., Edwards, B. B. \& Houk, R. S. (1989). Intrinsic and extrinsic stable isotopic zinc absorption by infants from formulas. Journal of Nutrition 119, 1661-1669. 